\title{
Colocación de coordenadas geodésicas UTM WGS 84 con ERP y levantamiento fotogramétrico con RPA para fines de habilitación urbana
}

Placing geodetic coordinates UTM WGS 84 with ERP and photogrammetric survey with RPA for urban habilitation purposes Colocação de coordenadas geodésicas UTM WGS 84 com ERP e levantamento fotogramétrico com RPA para fins de habilitação urbana

\section{ARTÍCULO GENERAL}

\author{
Jorge Luis Plasencia Valdiviezo \\ jluis.plasencia@gmail.com \\ https://orcid.org/0000-0001-7670-5654 \\ Universidad Cesar Vallejo, Lima - Perú
}

Recibido 05 de Febrero 2021 | Arbitrado y aceptado 19 de Abril 2021 | Publicado 28 de Julio 2021

\begin{abstract}
RESUMEN
En esta investigación se registra las etapas y los resultados que intervienen en un levantamiento fotogramétrico, a través de vehículos no tripulados, (RPA), aeronave pilotada a distancia (remotely piloted aircraft). conocidos más popularmente como Drones y que han revolucionado la fotogrametría y cartografia, debido a la disponibilidad de los equipos a costos accesibles, y alta precisión alcanzada.

Usados en este caso para obtener los planos de una habilitación urbana, asimismo la colocación de ERP (estaciones de rastreo permanente), etc., todos los cuales utilizados de una manera correcta acortan los tiempos y los costos comparados a trabajos realizados con otros métodos tradicionales como por ejemplo levantamientos realizados con estación total.

Se utilizó para ello un dron multirotor Phantom 4, el cual genero las imágenes para luego ser procesados en el software fotogramétrico Agisoft Photoscan y generar la ortofoto y generar en CAD, los planos finales.

Todo ello para generar información geoespacial a través de la fotogrametría sin rebajar el nivel de precisión de los trabajos, este trabajo se realizó en un área del distrito de Piura, Departamento de Piura, específicamente en el distrito 26 de octubre. ubicado en el Perú.

Palabras clave: Coordenadas geodésicas, fotogrametría, vehículos no tripulados, Estaciones de Rastreo Permanente.
\end{abstract}

\section{RESUMO}

In this research, the stages and results involved in a photogrammetric survey are recorded, through unmanned vehicles (RPA), remotely piloted aircraft. more popularly known as Drones and that have revolutionized photogrammetry and cartography, due to the availability of equipment at affordable costs, and high precision achieved.

Used in this case to obtain the plans of an urban facility, also the placement of ERP (permanent tracking stations), etc., all of which used in a correct way reduce time and costs compared to works carried out with other traditional methods such as surveys carried out with a total station.

A Phantom 4 multirotor drone was used for this, which generated the images to later be processed in the Agisoft Photoscan photogrammetric software and generate the orthophoto and generate the final plans in CAD.

All this to generate geospatial information through photogrammetry without lowering the level of precision of the work, this work was carried out in an area of the district of Piura, Department of Piura, specifically in the district of October 26. located in Peru.

Keywords: Geodetic coordinates, photogrammetry, unmanned vehicles, Permanent Tracking Stations.
Nesta pesquisa, são registradas as etapas e os resultados envolvidos em um levantamento fotogramétrico, por meio de veículos não tripulados (RPA), aeronaves pilotadas remotamente. mais popularmente conhecidos como Drones e que revolucionaram a fotogrametria e a cartografia, devido à disponibilidade de equipamentos a custos acessíveis e alta precisão alcançada.

Utilizado neste caso para obter os planos de um equipamento urbano, também a colocação de ERP (estações permanentes de rastreamento), etc., todos os quais utilizados de forma correta reduzem o tempo e os custos em comparação com as obras realizadas com outros métodos tradicionais como levantamentos realizados com estação total.

Para isso, foi utilizado um drone multirotor Phantom 4, que gerou as imagens para posteriormente serem processadas no software fotogramétrico Agisoft Photoscan e gerar a ortofoto e gerar os planos finais em CAD.

Tudo isso para gerar informação geoespacial através da fotogrametria sem baixar o nível de precisão do trabalho, este trabalho foi realizado em uma área do distrito de Piura, Departamento de Piura, especificamente no distrito de 26 de outubro. localizado no Peru.

Palavras-chave: Coordenadas geodésicas, fotogrametria, veículos não tripulados, Estações de rastreamento permanente. 


\section{Introducción}

La fotogrametría se inicia como ciencia en 1840, es la combinación de varias ciencias como son: óptica, la fotografía y las matemáticas, y consiste en obtener información de objetos físicos y del medio ambiente a partir de la generación de imágenes fotográficas, que es información en $2 \mathrm{D}$, pero que a partir del procesamiento en programas adecuados se obtienen información tridimensional o 3D. (Pozo Ríos, 2002).

La Sociedad Americana de Fotogrametría (Thomson y Gruner, 1980) la definen, de forma más concreta e incluyendo los últimos avances, como "la ciencia, arte y tecnología que obtiene información fiable de objetos y su entorno mediante procesos de registro, medida e interpretación de imágenes fotográficas y de datos obtenidos a partir de energía electromagnética radiante o de fenómenos magnéticos".

Y se realizan de acuerdo a parámetros, y que nos dan una riqueza informativa gracias a la técnica de teledetección que se emplean para obtener la información sobre una distancia vertical sobre objetos y áreas de la superficie de la tierra de la cual se va a extraer información.

Se harán uso del sistema de coordenadas UTM WGS 84, que es un elipsoide de referencia de uso universal, este articulo trata también de ello, pero además haciendo utilización de las estaciones de rastreo permanente (ERP), que toman lecturas en tiempo real a través de satélites artificiales las 24 horas del día.

Esta investigación surge como una respuesta acerca de hacer uso de las tecnologías actualmente muy poco conocidas, para que de esta manera sean aplicadas en la solución de problemas concretos, como en este caso se realizó para fines de levantamiento de información para una habilitación Urbana, la cual está ubicada en el departamento de Piura, distrito de Piura, provincia de Piura, concretamente en el distrito 26 de octubre, ubicado en Perú.

Actualmente su uso está extendido en algunos países como México, Colombia, Chile solo por citar algunos de Latinoamérica, pero que en nuestro país todavía está formándose conciencia para aprovechar estas tecnologías valiosas. 
Los trabajos que nos sirven como referencia para la presente investigación, tenemos

“Conversatorio de especialización Técnico Catastral del sistema nacional integrado de información Catastral Predial SNCP”, Nuevo Marco Geodésico Oficial. Densificación Puntos Geodésicos y estación de rastreo permanente a nivel nacional y Aplicaciones en el Catastro. Ing. Ricardo Javier Mendoza.

Revista El Geógrafo, Revista Tecnico-Cientifica del Instituto Geográfico Nacional, Edición $N^{\circ}$ 11/Setiembre de 2014, Vehículos aéreos no tripulados, en las tareas geoespaciales, pág. 6-7, My CyT EP director de la escuela Cartográfica, IGN, Percy Guillermo Baldeon.

Revista El Geógrafo, Revista Tecnico-Cientifica del Instituto Geográfico Nacional, Edición $N^{\circ}$ 12/Se de 2014, Vehículos aéreos no tripulados, en las tareas geoespaciales, pág. 6-7, My CyT EP director de la escuela Cartográfica, IGN, Percy Guillermo Baldeon.

“Comparación de resultados obtenidos de un levantamiento topográfico utilizando la fotogrametría con drones al método tradicional” Tesis para optar el título de Ingeniero Topógrafo y agrimensor, Puno-Perú, año 2015

La fotogrametría clásica se basa en el principio de estereoscopía a través de imágenes aéreas con más de $60 \%$ de sobreposición, con el que se generan modelos digitales del terreno. No obstante, para poder establecer estudios de cambio superficial multitemporal, los métodos fotogramétricos tradicionales requerían muchos ajustes técnicos de orientación de las imágenes, tanto en la toma como en el procesamiento de datos, los cuales no llegan a ofrecer precisión y confianza en los resultados (Eltner, 2016; Stöcker et al ,2015). La técnica Structure for Motion (SfM) (Ullman, 1979) permite solventar estos ajustes de orientación de manera automatizada y confiable en los actuales softwares fotogramétricos. Con el desarrollo tecnológico de los drones, el geoposicionamiento de cada fotografía ya es automático, no sólo en coordenadas XYZ, sino también en $\omega \phi K$ (valores de rotación del eje del aparato que pueden afectar cada fotografía), lo que asegura la correcta geometría de los modelos por medio de los puntos coincidentes en las fotos. El SfM permite, por tanto, posicionar un modelo sobre otro con el conocimiento de que la geometría de ambos ya ha sido rectificada por el software 
fotogramétrico. (en este caso Agisoft Photoscan) El uso de dicha técnica es de vital importancia en esta investigación porque elimina el error geométrico en los modelos 3D.

El presente trabajo analizara el grado de precisión en cuanto al producto generado por la técnica fotogramétrica haciendo uso de RPA.

Realizar la comparación con una norma internacional específicamente de México y con la norma peruana del cual el IGN del Perú, es el ente rector.

Dar a conocer las etapas y procedimiento de campo y gabinete, que implica hacer un levantamiento fotogramétrico en coordenadas WGS 84, haciendo uso de estas tecnologías, para una habilitación urbana.

Dar valor al producto generado es decir la información en cuanto a credibilidad y el precio accesible, para los diferentes proyectos de instituciones públicas y privadas aplicados a cualquier proyecto de ingeniería.

El área de terreno levantado fue de 20 has y perímetro de $1,887.57 \mathrm{ml}$.

Ubicado en Departamento Piura; Provincia: Piura, Distrito: Veintiséis de Octubre y tiene por coordenadas en su centroide de: N 9428501.598; E 535961.143 (área achurada)

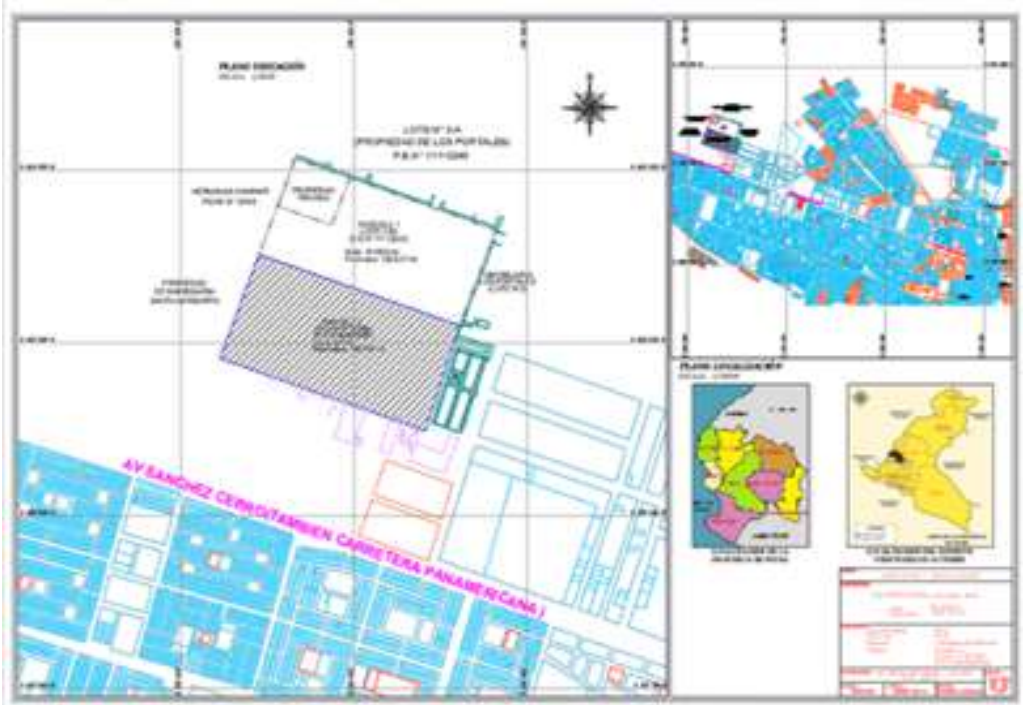

Figura $\mathrm{N}^{\circ}$ 03. Plano de ubicación y localización

Nota: el achurado representa el área de estudio. (parte izquierda). 
El clima en verano es muy caliente, y nublados; los inviernos son largos, cómodos, ventosos y mayormente despejados y está seco durante todo el año. Durante el transcurso del año, la temperatura generalmente varía de $17^{\circ} \mathrm{C}$ a $33^{\circ} \mathrm{C}$.

El trabajo de campo se realizó el 20 de enero del 2021, y se empezó a las 9:30am, día en que estuvo muy soleado y por lo tanto había claridad lo cual es muy conveniente para que las fotos salgan de manera óptima y no haya sombras.

\section{Materiales y metodos}

La presente investigación se realizó mediante el diseño descriptivo. Donde la población

Está conformada un área de 20 hectáreas y un perímetro de $1,887.57 \mathrm{ml}$.

Ubicado en Departamento Piura; Provincia: Piura, Distrito: Veintiséis de Octubre y tiene por coordenadas en su centroide de: N 9428501.598; E 535961.143.

\section{Características del RPA}

Dron utilizado: PHANTOM 4 DJI

Envergadura: $60 \mathrm{~cm}$

Sistema de navegación: GPS

Altura media de vuelo: $89.30 \mathrm{~m}$

Velocidad: $14.60 \mathrm{~m} / \mathrm{s}$

Tiempo de vuelo: Aprox. 10m 8s

Número de vuelos: 01

Radio de control y telemetría: $3.5 \mathrm{Km}$

Numero de fotos capturadas: 310

Tamaño de la imagen: 4000 x 3000 pixels

Resolución en terreno: $6.67 \mathrm{~cm} / \mathrm{pixel}$ 


\section{Equipo GNSS}

Jorge Luis Plasencia Valdiviezo

Colectora Topcon: FC 200

GPS Diferencial Marca Topcon Hiper + L1 y L2

Bastón de 2.5m

Trípode de aluminio 01 unidades

\section{Otros}

Cámara

Wincha $3 \mathrm{~m}$.

Libreta apuntes

Yeso

Cemento

Estacas de fierro diámetro $1 / 2 \%, \mathrm{~L}=0.40 \mathrm{~m}$

Molde para hitos de concreto

GPS navegador

\section{Estación Fotogramétrica}

\section{Hardware}

El equipó consta de un ordenador PC, al que están conectados un monitor y los distintos periféricos.

Ordenador es un i7, cuyas características son:

CPU (Unidad Central de Proceso):

Intel (R) Core (TM) i7 - 7700 CPU @ 3.60GHz (8 CPUs)

OS (Sistema Operativo): Microsoft Windows 10 Pro 64 bits 
Memoria RAM (Memoria principal):

32768MB RAM.

Disco Duro (250 GB)

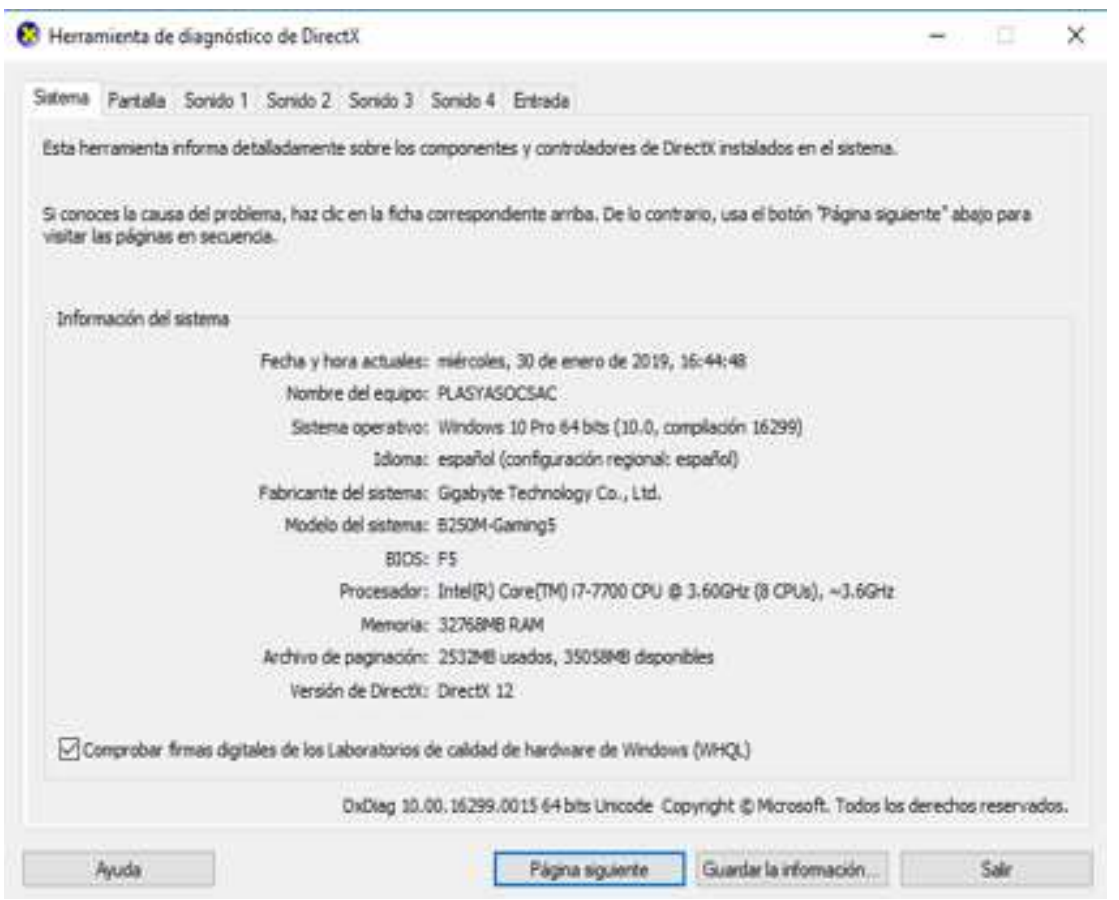

\section{Figura $\mathrm{N}^{\circ} 01$. Sistema operativo}

8. Heriamienta de diagnóstico de Drectx

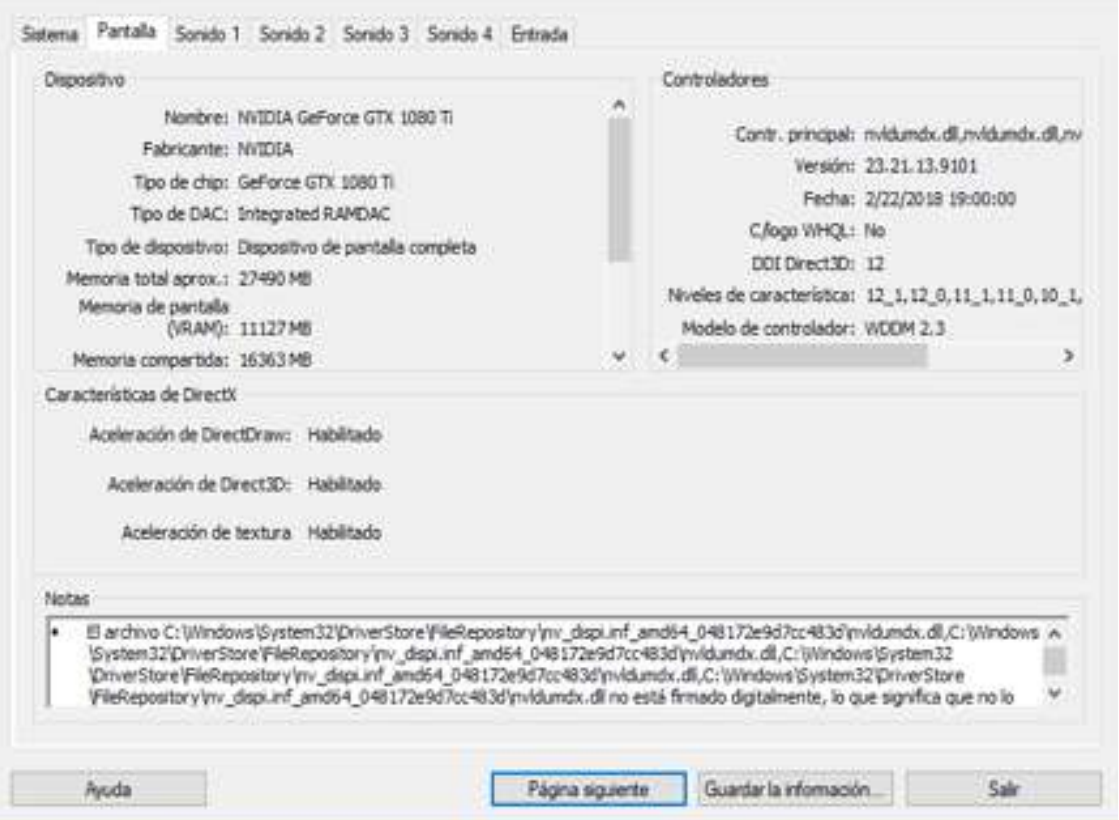

Figura $\mathrm{N}^{\circ}$ 02. Pantalla del Equipo 


\section{Software}

\section{Agisoft Photoscan Profesional}

Es un software para procesar imágenes digitales obtenidas en este caso por un RPA, haciendo uso de las técnicas de fotogrametría digital y un computador llamado en este caso Word Station, así de esta manera se genera una reconstrucción 3D del terreno, con esta se obtiene nubes de puntos a partir de las imágenes.

\section{Map Pilot}

Ayuda a crear y volar la ruta de vuelo óptima para crear excelentes mapas gracias a la alta resolución de la cámara del Dron PHANTOM 4 - DJI.

Asiste al usuario en tres de las áreas más problemáticas de la asignación de aviones no tripulados: Planificación de vuelo, Gestión de la misión y el Vuelo de la Misión real en sí.

\section{Global Mapper}

Es un software de sistema de información geográfica (GIS) desarrollado actualmente por Blue Marble Geographics que se ejecuta en Microsoft Windows.

Maneja los datos vectoriales, ráster y de elevación, y proporciona funciones de visualización, conversión y otras características generales de SIG

Acá es donde generamos la ortofoto y generación de curvas de nivel, verificamos la georreferenciación importándolo de Agisoft Photoscan, para luego 1levarlo al 3D Civil.

\section{AutoCAD Civil3D}

Es un software muy útil en el diseño de proyectos de ingeniería, como urbanismo, carreteras, movimiento de tierras, topografía, replanteo de información, etc.

La principal característica de este programa es que está diseñado por Autodesk y todos sus componentes que intervienen en el diseño estén relacionados, los objetos al ser modificados automáticamente regeneran y actualizan el diseño y recalculan la 
información de perfiles, etc., todo esto facilita cuando hacemos cambios en nuestra propuesta de proyecto sin tener que hacer todo el proyecto de nuevo.

Importamos la ortofoto y la nube de puntos que previamente hemos trabajado en el Global Mapper, y aquí le damos el acabado a las curvas de nivel y planos del proyecto.

\section{Etapas levantamiento fotogramétrico con RPA}

Se ejecutaron las actividades siguientes:

Tabla $\mathbf{N}^{\circ}$ 01. Etapas levantamiento Fotogramétrico con RPA

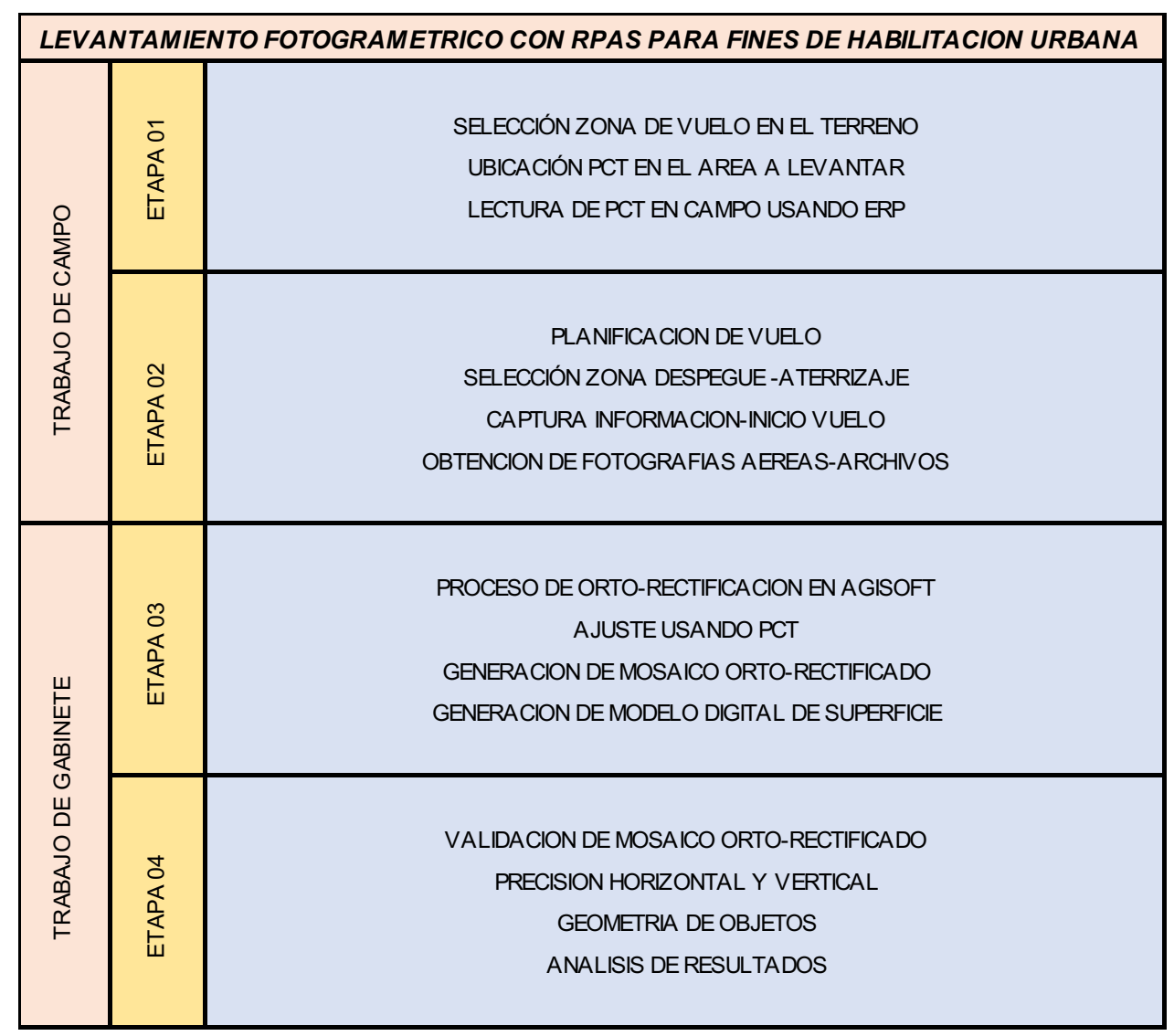

Fuente: Elaboración propia

\section{Trabajo de campo}

\section{Etapas 01}

Selección zona de vuelo en el terreno 
Se visita el terreno en lo posible, de tal manera que se pueda usar de manera conveniente el RPA, no tiene que estar el área a levantar cubierta por árboles, que este despejado de tal manera que las imágenes se obtengan de manera óptima y se tratara de tomar las fotos en las primeras horas de la mañana.

\section{Ubicación PCT en el área a levantar}

Se planifico la colocación en el campo de 12 puntos de control terrestre (PCT), distribuidos en el área de trabajo de tal manera que el proceso de ajuste fotogramétrico se realice de manera correcta y según los parámetros requeridos.

Estas se ubican convenientemente de acuerdo al área a levantar y teniendo en cuenta la configuración del terreno mismo, para una distribución correcta de los PCT., se marcó en el terreno con yeso en forma de cruz, de una longitud de $1 \mathrm{~m}$, para que pueda visualizarse en las imágenes que son tomadas por el dron.

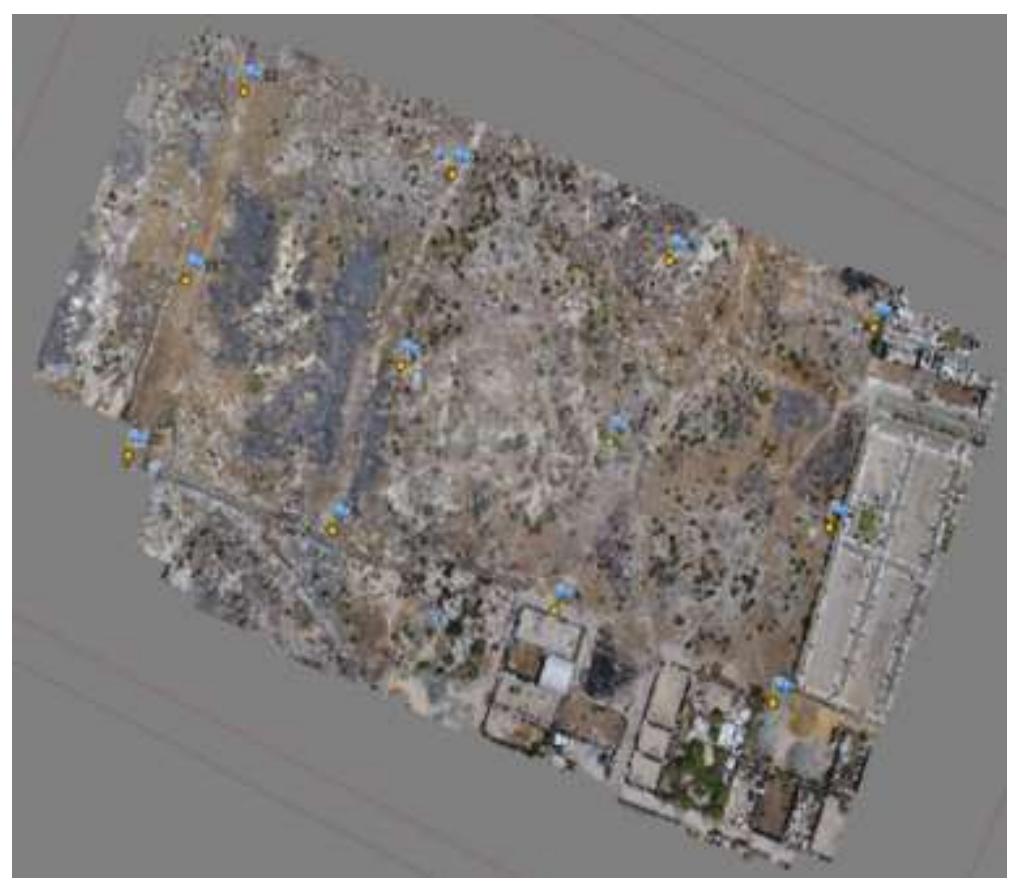

Figura $\mathrm{N}^{\circ}$ 04. Ubicación de los PCT

\section{Lectura de PCT en campo usando ERP}

Las ERP, están enlazadas en la Red Geodésica Nacional y permite la integración de la cartografía a generarse que es de mayor precisión, lo cual beneficia a la población en la que hay problemas de carácter jurisdiccional tal es el caso en la aplicación que se le va a dar al presente trabajo para fines de habilitación urbana por solicitud de la empresa Constructora Galilea SAC. 
El IGN es el ente rector de la cartografía en el Perú a través de la red geodésica peruana de monitoreo continuo (REGPMOC), administra 45 ERP, que están distribuidas en nuestro territorio nacional, el cual cuenta con información en data RINEX para el procesamiento de los puntos GNSS, obtenidos en campo, estos datos garantizan la precisión de cualquier punto sobre la superficie terrestre tomados de manera correcta, esta red de estaciones están distribuidas considerando una distancia en un radio de $50 \mathrm{Km}$ a $100 \mathrm{Km}$, dando de esta manera el soporte en cuanto a información geoespacial en cualquier proyecto, facilitando datos para obtener información precisa para diversas aplicaciones, como proyectos de infraestructura a nivel local, provincial y regional, relacionadas al ordenamiento territorial, construcción de carreteras, represa, canales, puentes, túneles, saneamiento predial, etc.

Se toman las lecturas usando el método Stand Go, en la cual se usa el GPS Diferencial y la colectora en la que se programan en un lapso de tiempo de 30 épocas, (aprox. 5min) para cada PCT.

De allí la importancia de las ERP, ya que brinda facilidad para generar cartografía a nivel de detalle urbano, los cuales vienen siendo utilizados por las diversas instituciones públicas y privadas que se dedican a este rubro en todo nuestro ámbito territorial.

Este trabajo tiene por finalidad la habilitación urbana del área levantada, es por eso que, al hacer uso de la ERP, se garantiza la precisión en la ubicación de los linderos de una manera precisa. 


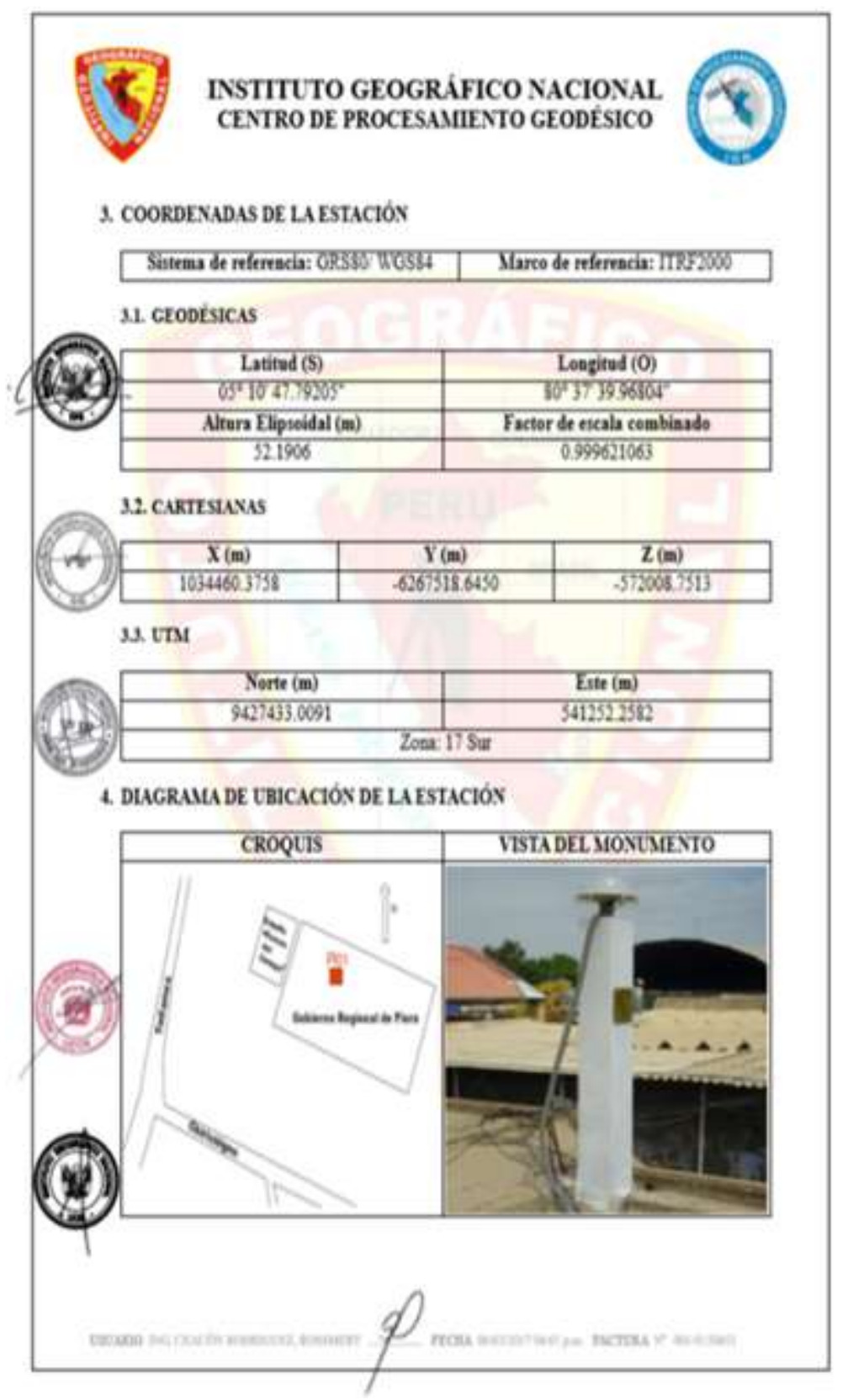

Figura $\mathrm{N}^{\circ}$ 05. Ficha Técnica ERP.

Se compra seguidamente la ficha técnica y la data de ERP, trabajada en ese día.

La cual es la data que se almacena en 24 horas de toma de datos con los satélites. 


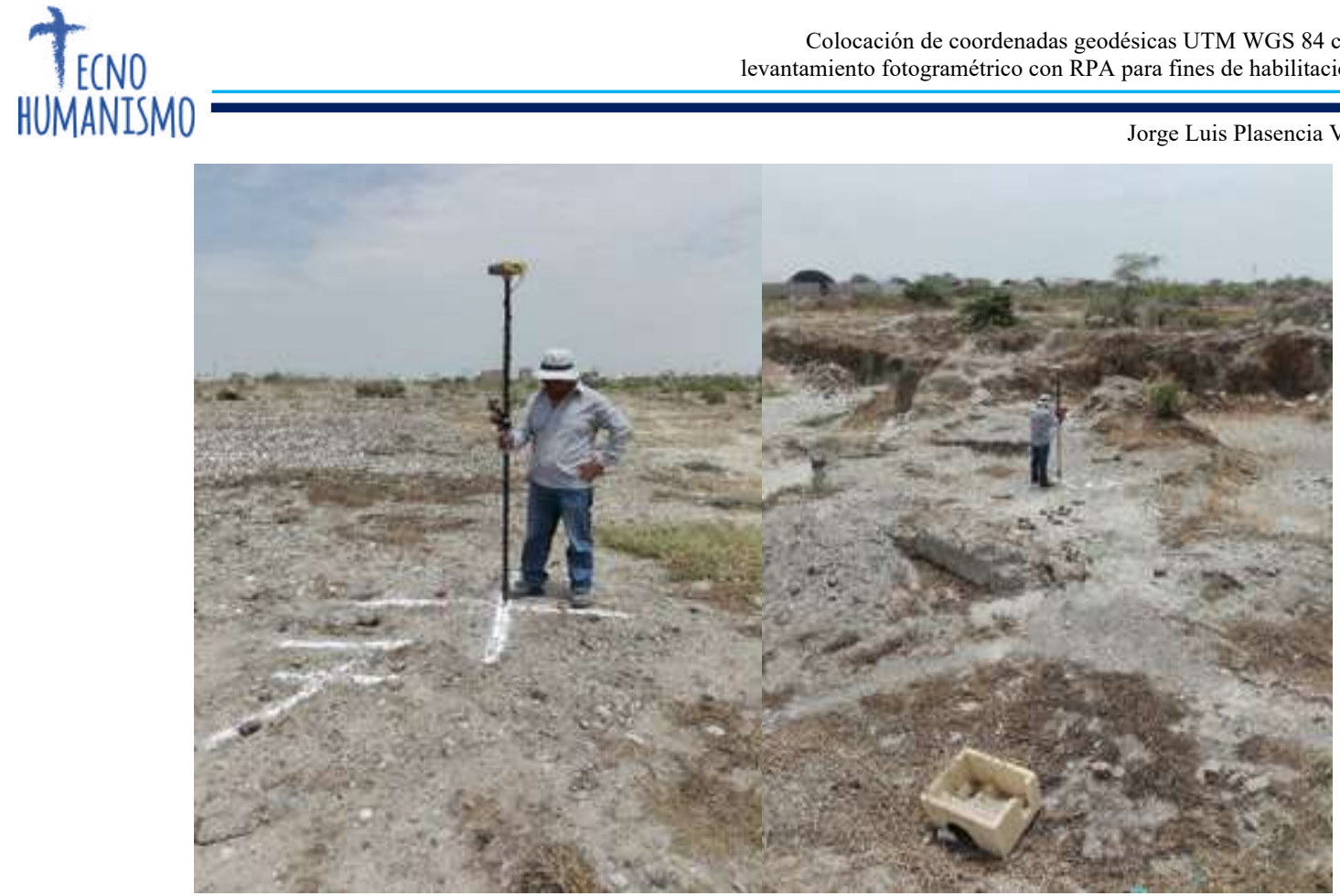

Figura $\mathrm{N}^{\circ} 06$. PCT 7 y PCT 8

\section{Etapa 02}

\section{Planificación de vuelo}

se realiza en la oficina o en lugar conveniente que tenga internet, para poder planificar el vuelo, el área, el GSD, la altura de vuelo, velocidad, etc.

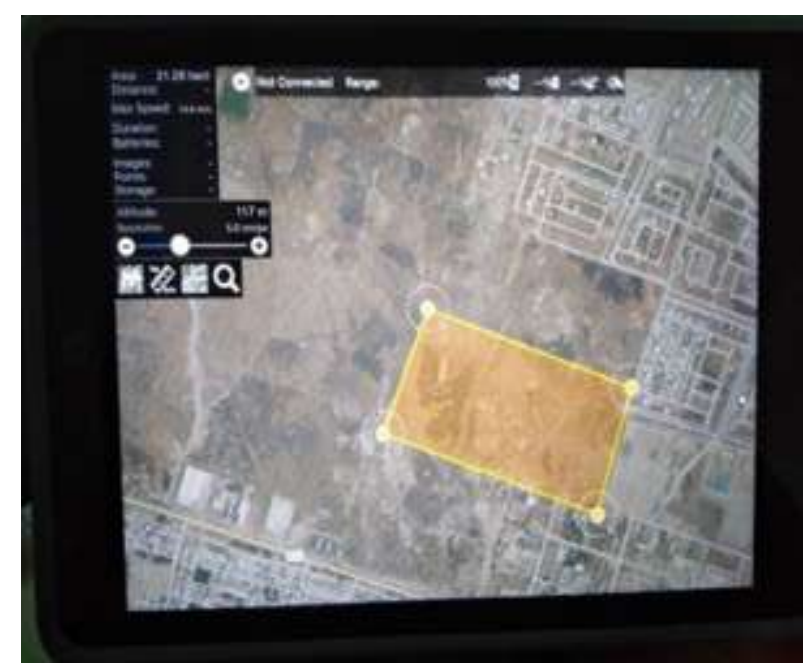

Figura $\mathrm{N}^{\circ} 07$. Ubicación de área a levantar y posterior planificación 


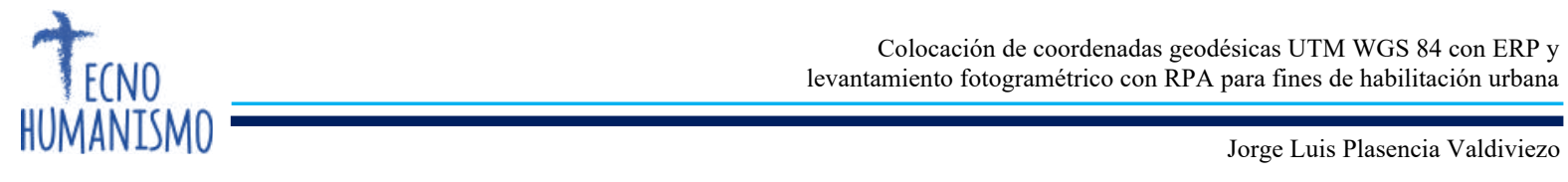

\section{Selección zona despegue - aterrizaje}

Es importante este paso, debido no tiene que tener interferencias de cables, desniveles del terreno, o presencia de árboles, que impidan el correcto descenso de RPA.

O la presencia de aves territoriales, que dañen o interfieran con el equipo al momento de volar.

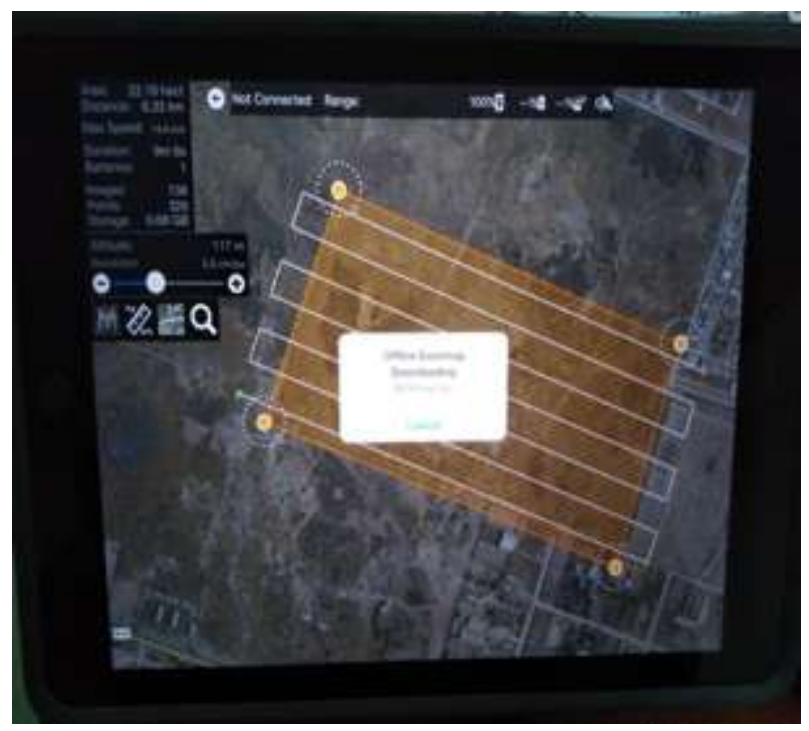

Figura $\mathrm{N}^{\circ} 08$. Líneas de vuelo y selección zona de despegue

\section{Captura información - inicio vuelo}

Las imágenes se almacenan en un $\mathrm{SD}$, que viene en el dron, es importante sacar la tapa del lente, y cerciorarse que la cámara este en óptimas condiciones, así como el día este despejado, es apropiado volar en horas de la mañana a partir de las 8 am ya que la iluminación es importante para unas buenas fotos, y que no haya muchas corrientes de aire, ya que esto no permite que la cámara funcione correctamente.

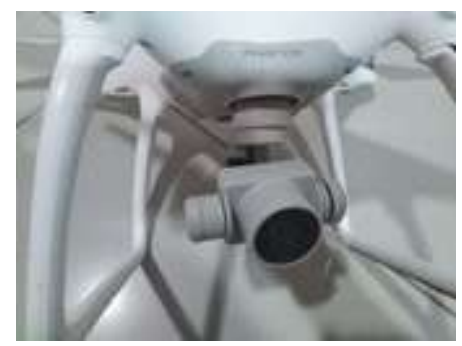

Figura $\mathrm{N}^{\circ}$ 09. Cámara del Dron 
Obtención de fotografías aéreas - archivos

Las imágenes se obtienen en formato JPEG, DNG (RAW) y en video con una calidad HD, tiene una capacidad máxima de Micro SD 64 GB, hay que estar observando siempre en la imagen de la Tablet en este caso que el dron este tomando las fotos y se visualiza en el Map Pilot.

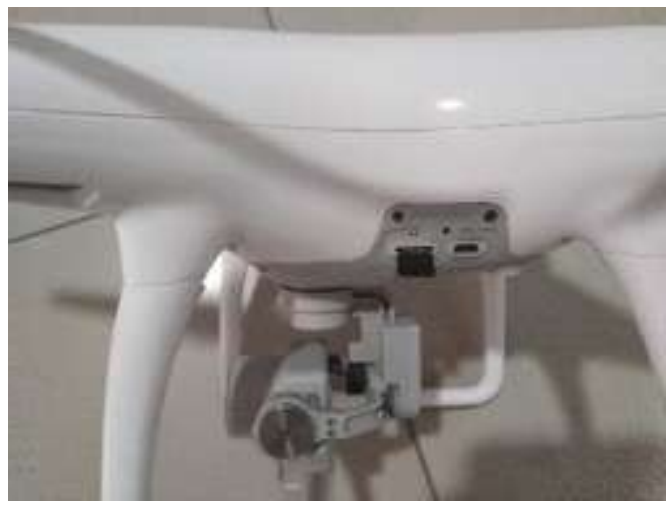

Figura $\mathrm{N}^{\circ} 10$. Memoria SD

\section{Trabajo de gabinete}

\section{Etapa 03}

\section{Proceso de Orto-rectificación en Agisoft}

Es un software para procesar imágenes digitales obtenidas en este caso por un RPAS, haciendo uso de las técnicas de fotogrametría digital y un computador llamado en este caso Word Station, así de esta manera se genera una reconstrucción 3D del terreno, con esta se obtiene nubes de puntos a partir de las imágenes.

\section{Ajuste usando PCT}

Los PCT, están ajustados previamente a la ERP, que se encuentra ubicado en este trabajo en la ciudad de Piura, los cual garantiza una precisión milimétrica en las coordenadas que sería el desplazamiento horizontal y las cotas que serían el desplazamiento vertical.

El cuadro adjunto es el resumen de los puntos ajustados y corregidos amarrados a una ERP, de orden " 0 ”. 
El ajuste por postproceso se realizó en el programa Topcon Tools, de la cual se obtuvo los datos presentados en la tabla $\mathrm{N}^{\circ} 02$.

Tabla $\mathbf{N}^{\circ}$ 02. Cuadro de coordenadas de PCT

\begin{tabular}{|c|c|c|c|c|}
\hline $\mathbf{N}^{\circ}$ Pto & NORTE & ESTE & ELEVACION $(\mathbf{m})$ & CODIGO \\
\hline 1 & 9428563.345 & 536301.074 & 39.769 & PCT1 \\
\hline 2 & 9428398.794 & 536260.351 & 38.698 & PCT2 \\
\hline 3 & 9428254.26 & 536208.913 & 39.083 & PCT3 \\
\hline 4 & 9428329.507 & 536010.679 & 38.868 & PCT4 \\
\hline 5 & 9428468.867 & 536061.354 & 38.386 & PCT5 \\
\hline 6 & 9428618.699 & 536115.227 & 37.980 & PCT6 \\
\hline 7 & 9428689.924 & 535917.844 & 39.685 & PCT7 \\
\hline 8 & 9428532.144 & 535870.644 & 36.343 & PCT8 \\
\hline 9 & 9428396.463 & 535808.287 & 38.778 & PCT9 \\
\hline 10 & 9428458.118 & 535622.144 & 37.470 & PCT10 \\
\hline 11 & 9428602.037 & 535674.634 & 38.924 & PCT11 \\
\hline 12 & 9428758.817 & 535727.864 & 38.881 & PCT12 \\
\hline
\end{tabular}

Fuente: Elaboración propia

\section{Generación de mosaico orto rectificado}

Es un mosaico de imágenes aéreas ortogonales corregidas para las distorsiones ópticas, geo referenciado y orto rectificado.

Las fotografías aéreas son georreferenciadas tienen coordenadas geográficas del lugar donde fueron tomadas y tienen puntos de control terrestres (PCT).

Al final del procesamiento se obtiene un ortofoto mosaico con una precisión relativa de hasta $5 \mathrm{~cm}(\mathrm{X}, \mathrm{Y}, \mathrm{Z})$ que representa la superficie real de la tierra, y se puede utilizar para medir distancias y calcular áreas.

Se obtienen fotografías de alta resolución espacial: desde $5 \mathrm{~cm} /$ pixel hasta $25 \mathrm{~cm} /$ pixel. 


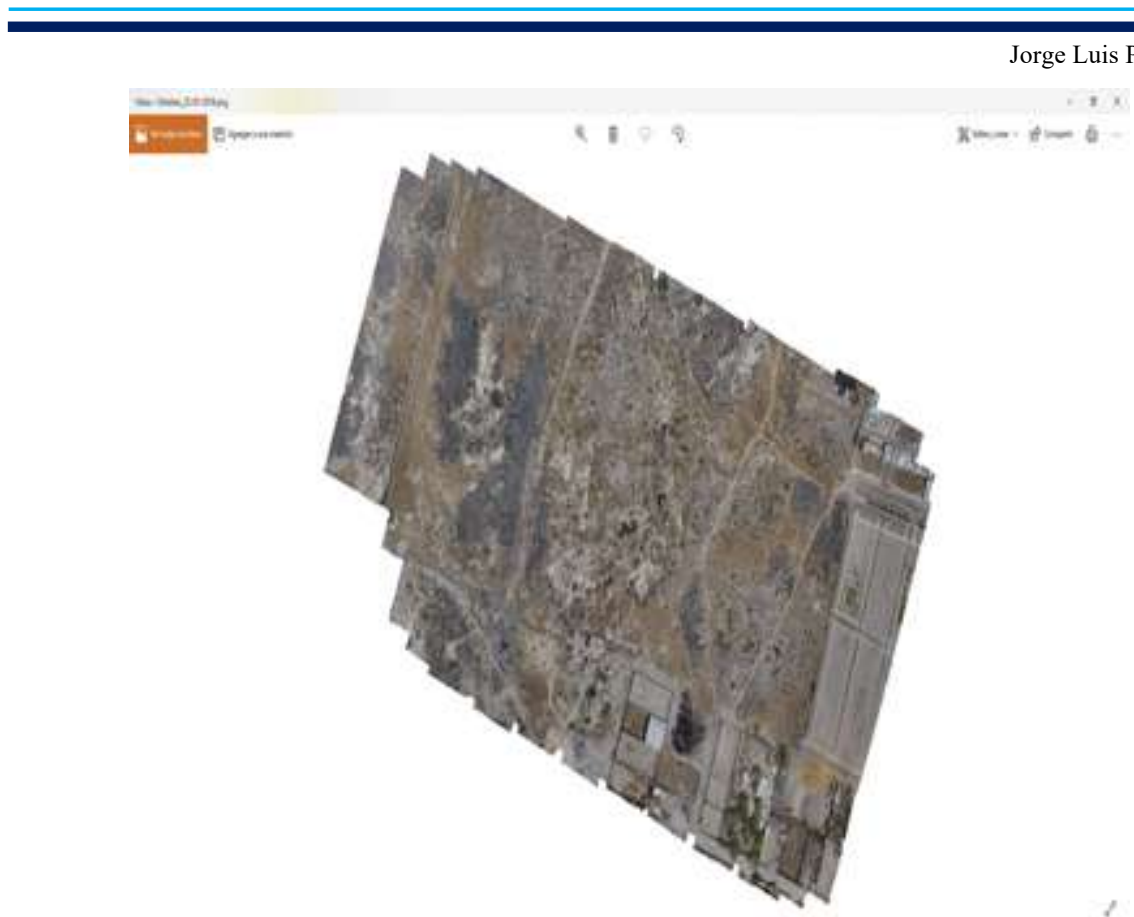

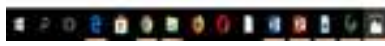

Figura $\mathrm{N}^{\circ} 11$. Mosaico orto rectificado

\section{Generación de modelo digital de superficie (DSM)}

Es un modelo de la superficie (3D) con información sobre de todo lo que se ve en el ortofoto mosaico (vegetación, planta de edificaciones, etc.).

Son procesadas con los más recientes algoritmos fotogramétricos y se obtiene de las fotos realizadas por el RPAS.

Se obtienen DSM de $5 \mathrm{~cm}$ / píxel hasta $2 \mathrm{~m}$ / píxel en formato RASTER, TIF y en formato vectorial como nube de puntos. XYZ.

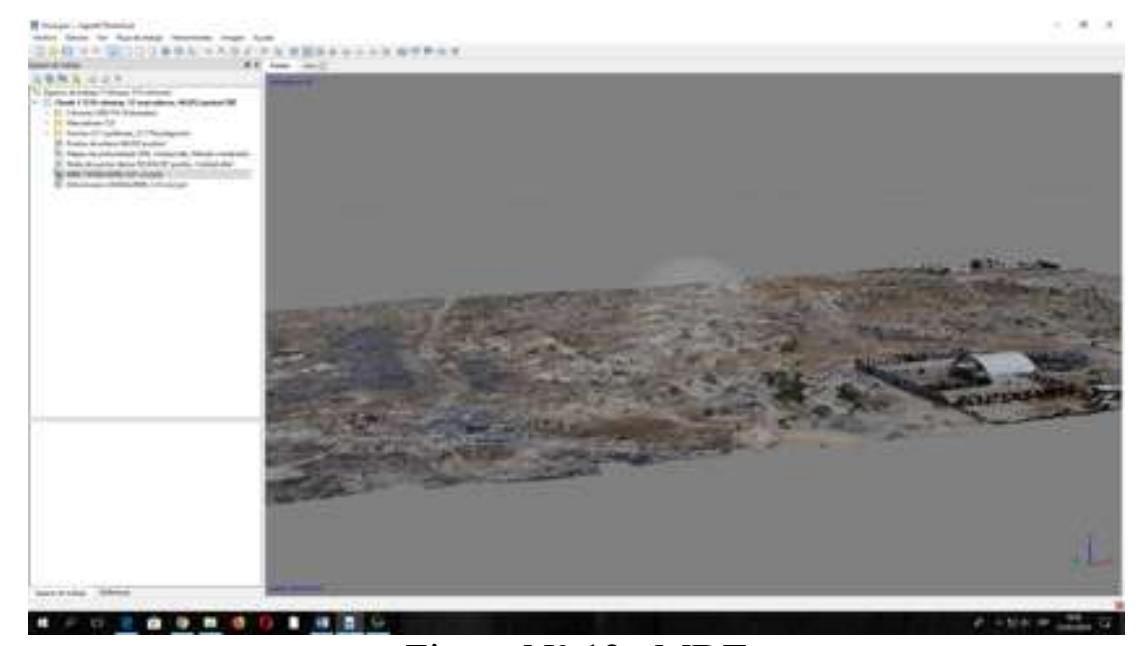

Figura $\mathrm{N}^{\circ}$ 12. MDT 


\section{Etapa 04}

\section{Validación de mosaico orto rectificado}

Una vez la nube de puntos exportado al programa AutoCAD Civil 3D 2017, se generó las curvas de nivel cada $0.50 \mathrm{~m}$, se chequeo la base B-1 y B-2, la cual se colocó en un lapso de 2 horas con GPS en método estático y postproceso.

Como se aprecia en la Figura $\mathrm{N}^{\circ} 14$, (B-1), tiene como cota 39.02msnm, y haciendo uso de la herramienta añadir etiquetas picamos en la malla generada, tal como apreciamos en la figura $\mathrm{N}^{\circ} 13$ para ver su cota para la comparación respectiva y se obtiene una diferencia de $+4 \mathrm{~cm}$.

Se realizó para la siguiente $\mathrm{B}-2$, y se obtuvo según la figura $\mathrm{N}^{\circ} 15$, una diferencia de $-6 \mathrm{~cm}$.

Se chequeo la base B-1 y la B-2, en cuanto a su ubicación, habiendo utilizado los 12 PCT, y la ubicación calza con la imagen con el hito de concreto construido en el área de trabajo.

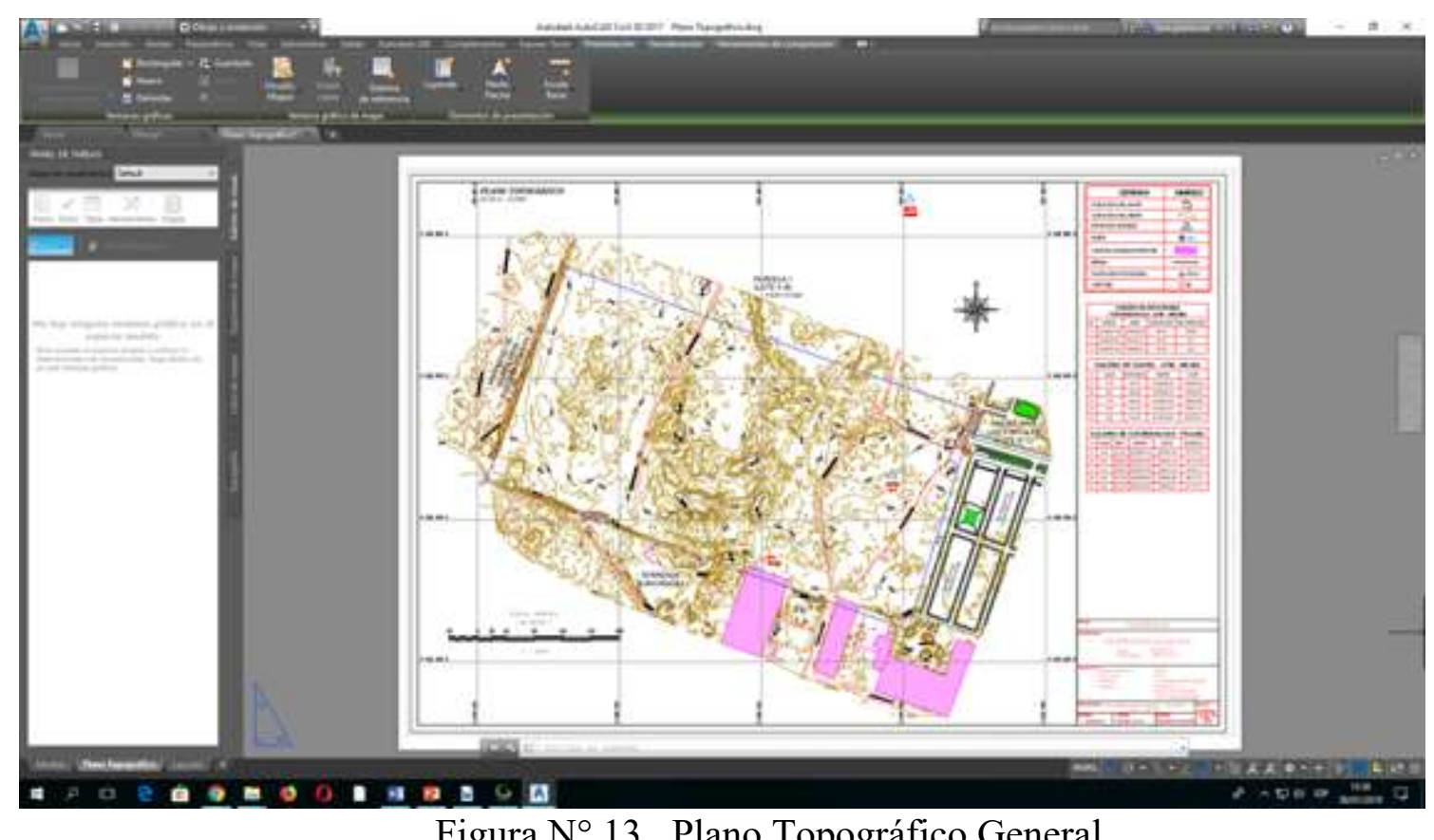

Figura $\mathrm{N}^{\circ}$ 13. Plano Topográfico General 
teCNO

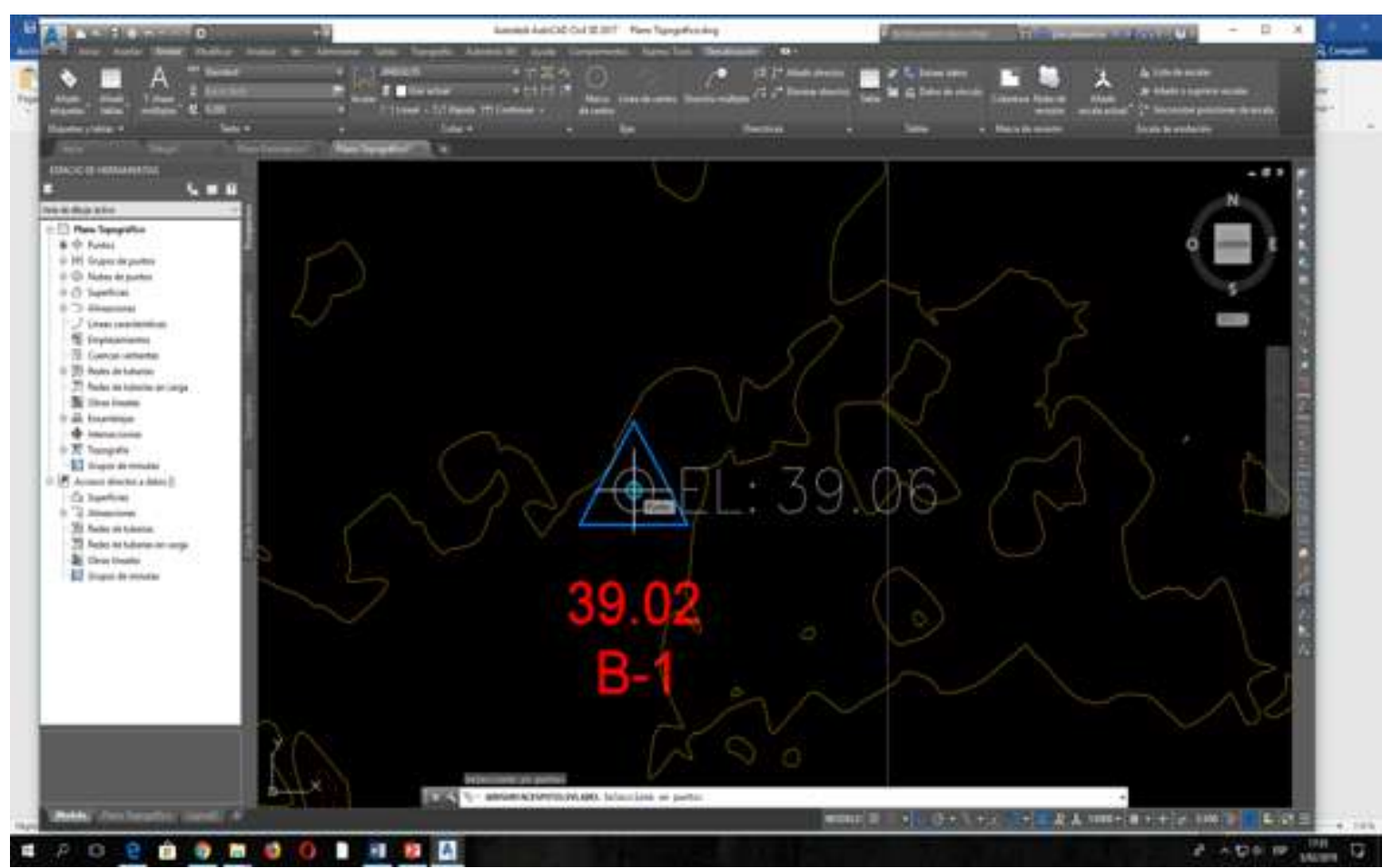

Figura $\mathrm{N}^{\circ}$ 14. Chequeo B-1

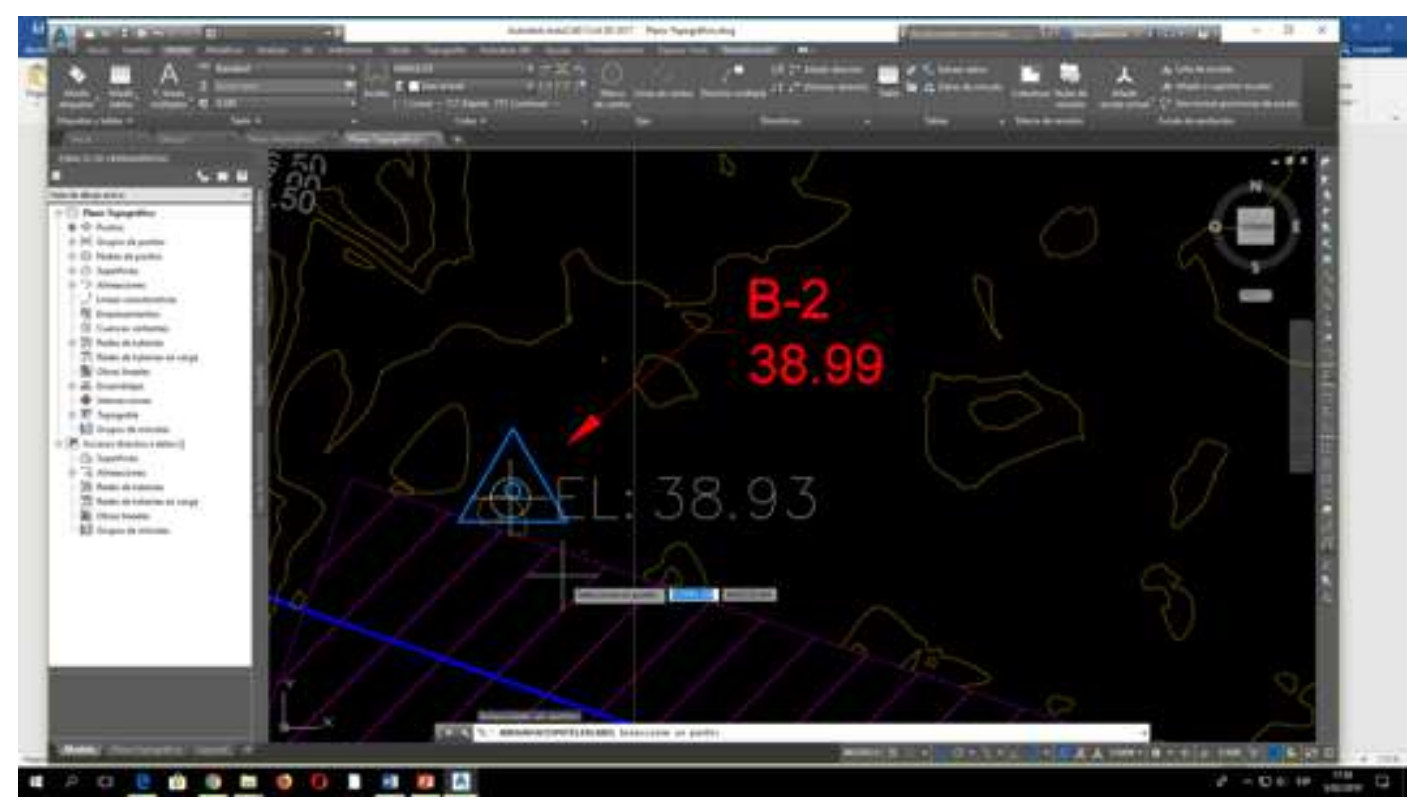

Figura $\mathrm{N}^{\circ} 15$. Chequeo B-2 


\section{Resultados}

\section{Precisión horizontal y vertical}

Los datos a continuación presentados, son los que se generó en el software Agisoft PhotoScan Informe de procesamiento del 22 enero 2018.

Tabla $\mathbf{N}^{\circ}$ 02. Cuadro de Puntos de Control Terrestre

\begin{tabular}{|c|c|c|c|c|c|}
\hline Nombre & Error $X(\mathrm{~cm})$ & Error $Y(\mathrm{~cm})$ & Error Z (cm) & Total (cm) & Imagen (pix) \\
\hline 1 & 6.05722 & -3.93788 & -2.3634 & 7.60148 & $0.301(7)$ \\
\hline 2 & -11.657 & -1.00363 & 4.64651 & 12.589 & $0.340(16)$ \\
\hline 3 & 13.9281 & -3.4575 & -2.23826 & 14.5243 & $0.301(10)$ \\
\hline 4 & -3.11167 & 7,51741 & -0.145397 & 8.13726 & $0.210(13)$ \\
\hline 5 & -5.11232 & 3.96873 & -3.50053 & 7.35801 & $0.370(16)$ \\
\hline 6 & -3.99576 & 1.02599 & 4.1121 & 5.82478 & $0.293(10)$ \\
\hline 7 & 4.39011 & 5.83945 & -2.59949 & 7.75432 & $0.330(10)$ \\
\hline 8 & -3.178 & -3.1502 & 0.652377 & 4.52206 & $0.226(23)$ \\
\hline 9 & -1.25949 & -2.61714 & 0.76232 & 3.00281 & $0.334(14)$ \\
\hline \multicolumn{6}{|l|}{10} \\
\hline 11 & 1.61564 & -3.47904 & 0.757909 & 3.91005 & $0.337(10)$ \\
\hline 12 & 2.79709 & -0.808276 & -0.269985 & 2.92402 & $0.126(7)$ \\
\hline Total & 6.46489 & 3.87782 & 2.51868 & 7.94834 & 0.298 \\
\hline
\end{tabular}

Fuente: Agisoft PhotoScan Informe de procesamiento 22 enero 2018

en los cuales se aprecia los desplazamientos en cm, máximo de $13 \mathrm{~cm}$ en X y mínimo de -1.21 y en Y máximo de $7.51 \mathrm{~cm}$ y mínimo de -1.00 .

en cuanto a $Z$ se aprecia máximo de $4.64 \mathrm{~cm}$ y mínimo de $-0.26 \mathrm{~cm}$.

\section{Geometría de objetos}

Una vez generado la ortofoto, se puede apreciar los sardineles, veredas, buzones, marcas en el pavimento, (Ver Figura $\mathrm{N}^{\circ} 17$ ), de manera clara lo cual hace fácil poder dibujar todos los detalles que componen el levantamiento fotogramétrico, permitiendo de esta manera que ningún objeto físico pase por alto todo se aprecia en la ortofoto. 

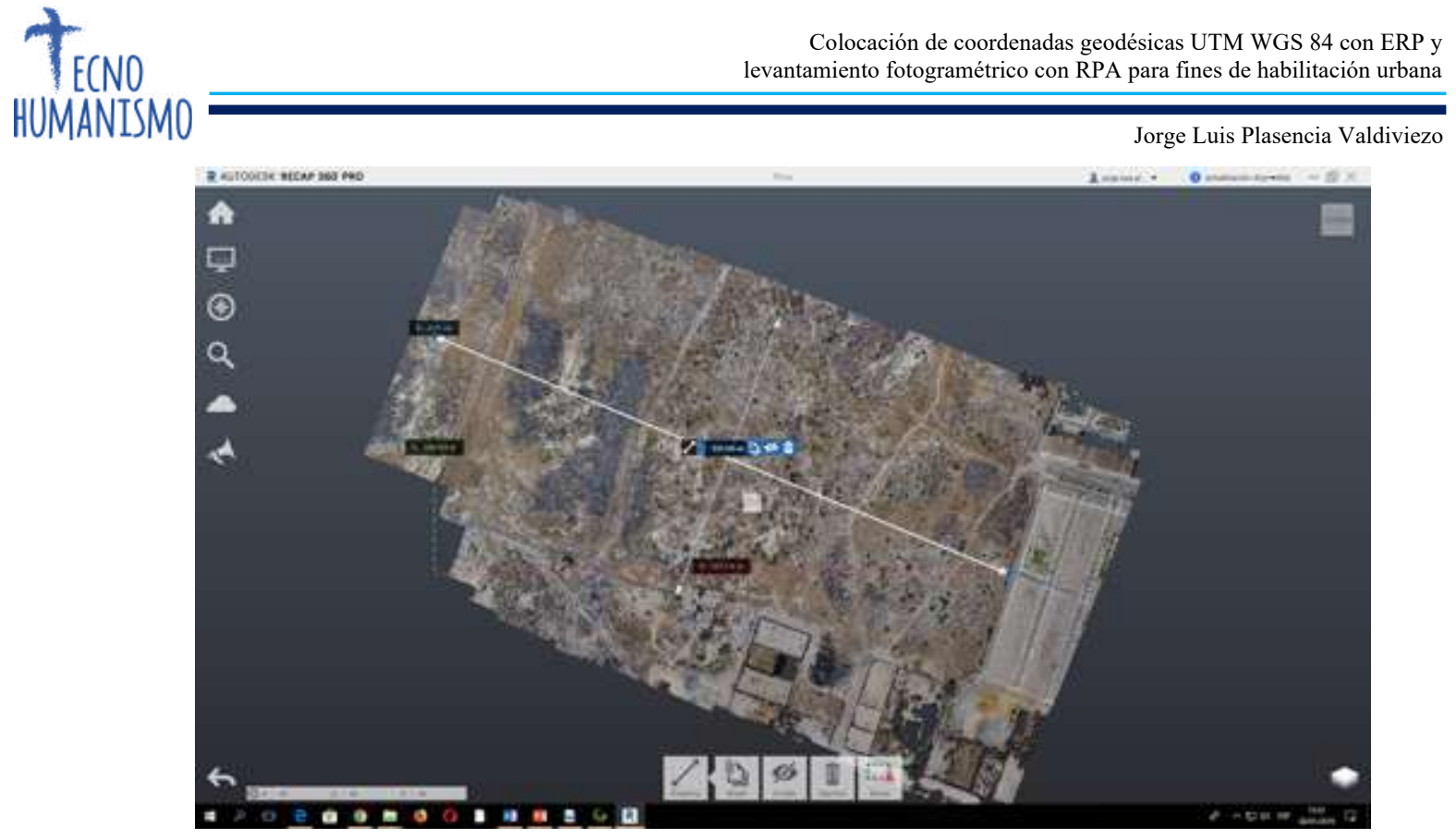

Figura $\mathrm{N}^{\circ}$ 16. Ortofoto exportado a Autodesk Recap $360^{\circ}$ pro

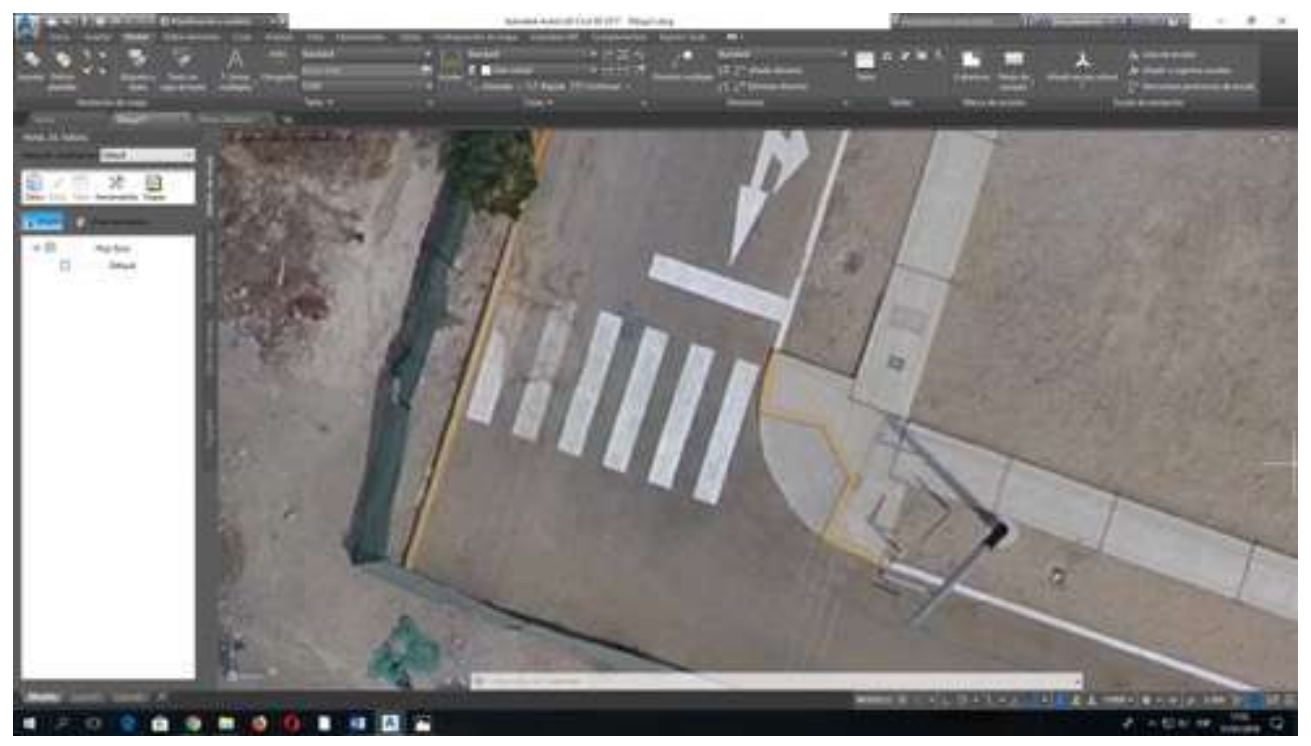

Figura $\mathrm{N}^{\circ}$ 17. Ortofoto exportado a Autodesk 3D Civil 2017

\section{Discusiones}

1. El Instituto Nacional de Geografía y Medio Ambiente de México, en sus especificaciones técnicas de imágenes orto rectificadas, indica que imágenes 
con GSD de $7.5 \mathrm{~cm}$ son adecuadas para escalas 1:500 y $15 \mathrm{~cm}$ para escala de $1: 1000$.

2. La normativa técnica para la cartografía base de 1:1000, establecida por el Instituto Geográfico Nacional - Perú, menciona que las condiciones del vuelo fotogramétrico deben presentar un GSD $0.1 \mathrm{~m} \pm 10 \%$, por lo tanto, al estar dentro de este rango, la ortofoto con RPAS se puede utilizar como referente de actualización a dicha escala.

3. Las demandas cartográficas exigidos por el Sistema Nacional Integrado de Información Catastral - Perú (SNCP) indica que los niveles de resolución de las ortofotos deben aplicarse con los siguientes rangos, con un GSD de $9 \mathrm{~cm}$ se puede establecer una cartografía de 1:1000 y con un GSD de $6 \mathrm{~cm}$ cartografía 1:500, esto es un referente para el empleo de RPAS para la generación de cartografía, pero debe verificarse el análisis de precisión al usar esta tecnología

4. El tiempo tomado en el levantamiento fotogramétrico en campo, fue de 20min. Lo cual nos habla del costo/beneficio al utilizar esta tecnología, actualmente el flujo de trabajo ha variado, antes tomaba más tiempo el trabajo de campo en un levantamiento clásico con estación total, actualmente el mayor tiempo lo toma el trabajo de gabinete, pero los resultados son provechosos, ya se toma una densidad en puntos terreno de más de 200 puntos/m2, lo cual garantiza un MDT, más cercano a la realidad, al generar perfiles y secciones.

Según el Instituto Nacional de Geografía y Medio Ambiente de México, en su compendio de especificaciones técnicas de imágenes ortorrectificadas, indica que imágenes con GSD de $7.5 \mathrm{~cm}$ son adecuadas para escalas $1: 500$ y $15 \mathrm{~cm}$ para escala de 1:1000. La normativa técnica para la cartografía base de 1:1000, establecida por el Instituto Geográfico Nacional - Perú, menciona que las condiciones del vuelo fotogramétrico deben presentar un GSD $0.1 \mathrm{~m} \pm 10 \%$, por ende, al estar dentro de este rango, la ortofoto con drone se puede utilizar como referente de actualización a dicha escala, analizando el nivel de resolución espacial. Los estándares cartográficos aplicados por el Sistema Nacional Integrado de Información Catastral - Perú (SNCP) indica que el nivel de resolución de las ortofotos debe aplicarse con los siguientes rangos, con un GSD de $9 \mathrm{~cm}$ se puede establecer una cartografía de 1:1000 y con un GSD de $6 \mathrm{~cm}$ cartografía 1:500, por ende, es un referente para el empleo de drones para 
la generación de cartografía, pero debe verificarse el análisis de precisión pertinente en el uso de esta tecnología

\section{Conclusiones}

1. De acuerdo al GSD de las ortofotos obtenidas con el drone Phantom 4, en el ítem II Fundamentos Teóricos, en la sección 2.1 Características del RPAS, se obtuvo una resolución de $6.67 \mathrm{~cm} /$ pixel, con ello se puede elaborar productos cartográficos a escalas 1:1000. Con intervalo de curvas cada $1 \mathrm{~m}, \mathrm{y}$ en cuanto a las tolerancias en cuanto a $\mathrm{H}=0.20 \mathrm{~m} ; \mathrm{V}=0.25 \mathrm{~m}$ y $\mathrm{GSD}=6-7 \mathrm{~cm}$

2. La utilización de tecnología RPAS posibilita obtener ortofotos actualizadas y con rapidez.

3. Con el DSM obtenido en el proceso fotogramétrico se pueden generar curvas de nivel topográficas, de acuerdo a la altura de vuelo y el GSD obtenido.

4. Se ha obtenido en este levantamiento los siguientes valores en $\mathrm{H}=5 \mathrm{~cm} ; \mathrm{V}=$ $5 \mathrm{~cm}$, lo cual como hemos visto está dentro de las tolerancias para escala 1:500, el cual permite intervalos de curvas cada $0.50 \mathrm{~m}$, y en cuanto a las tolerancias en cuanto a $\mathrm{H}=0.10 \mathrm{~m} ; \mathrm{V}=0.125 \mathrm{~m}$, a pesar de tener un $\mathrm{GSD}=$ $6.7 \mathrm{~cm} /$ pixel, lo cual nos acerca de manera más realista a lo que propone el Instituto Nacional de Geografía y Medio Ambiente de México, en sus especificaciones técnicas de imágenes orto rectificadas, indica que imágenes con GSD de $7.5 \mathrm{~cm}$ son adecuadas para escalas 1:500 y $15 \mathrm{~cm}$ para escala de $1: 1000$.

5. las ortofotos generadas sirven de manera práctica para poder ubicar todos los detalles y acortan la toma de datos de campo, lo cual se traduce en menores costos.

6. El uso correcto y conocimiento teóricos unido a esta tecnología, traerá trabajos apegados a la normatividad del ente rector de la topografía en el Perú, la cual es el Instituto Geográfico Nacional IGN.

\section{Referencias}

IGN (Instituto Geográfico Nacional, PE). (mayo de 2017). Especificaciones técnicas para la elaboración de cartografía básica escala 1:1000. 
INEGI (Instituto Nacional de Geografía y Estadística, MX). (marzo de 2020).

Compendio de criterios y especificaciones técnicas para la generación de datos e información de carácter fundamental. Imágenes digitales orto rectificadas fotogramétricamente.

Nunes Brito , J., \& Coelho, L. (2017). Fotogrametría digital. Rio de Janeiro: EdUERJ. Revisado en mayo de 2015, de http://www.efoto.eng.uerj.br/images/Documentos/fotogrametria_digital_revisado. pdf.

SNCP (Sistema Nacional Integrado de Información Catastral, PE). (s.f.). http://www.sncp.gob.pe Revisado en junio de 2018, de www.sncp.gob.pe/pdf/MARCO\%20JURIDICO/formatos $\% 20$ series $\% 20$ catastrale s/Estandares_Cartograficos_Aplicados_Catastro.pdf

Instituto Geográfico Nacional. Especificaciones técnicas para levantamiento fotogramétrico. Mayo 2021.

Sistema Nacional Integrado de Información Catastral - Perú. Estándares Cartográficos Aplicados al Catastro. Metodología en la obtención de Cartografía y Ortofoto a partir de Vuelos Fotogramétricos

Geo morfometría y cálculo de erosión hídrica en diferentes litologías a través de fotogrametría digital con drones.

Pozo Ríos, Ma del Mar. Desarrollo de equipos de fotogrametría: explotación del dato digital. XIV Congreso Internacional de Ingeniería Gráfica (Santander, España junio de 2020).

THOMPSON, M. Y GRUNER, H. Foundations of Photogrammetry. Manual of Photogrammetry.ed. C.C. Sama. American Society of Photogrammetry and Remote Sensing, pp.1-36. (2019)

https://www.tresgeo.com/geografia-fotogrametria-gis 